\title{
Can Preparation of Clinical Teachers in IPC Concepts and Competencies Impact Their Approach to Teaching Students in Clinical Practice? A Promising Approach
}

\author{
Carole Orchard \\ Western University, Canada \\ Linda L. Pederson \\ Western University, Canada \\ Dianne Allen \\ Western University, Canada \\ Halina Lam \\ Western University, Canada
}

\begin{abstract}
The challenge of providing interprofessional (IP) student placements within health agencies can be affected by two factors: patterns of health care agency placements focusing on students in one health professional program setting at a time; and budgets for funding clinical teaching in post-secondary institutions. These challenges can result in uni-professional, practice-based learning rather than learning to work within IP teams. Given the increasing focus on IP teamwork (World Health Organization 2010), the question arises as to whether there is a way clinical teachers can be prepared to work with students for IP teamwork. One strategy involves training clinical teachers with requisite strategies for working in team-based settings. Interprofessional clinical teaching workshops held at Western University, Canada, were started in 2010, and offered annually each fall. The overall workshop goal was to assist teachers in guiding and assessing students for effective collaborative teamwork. This article reports on a post-workshop evaluation of participants' self-reported clinical teaching and practice from three workshops. Of the 129 workshop participants approached to provide information, only 30 completed the post-workshop assessment (at variable times following the workshop from six months to two years). Of these, 27 reported changes in interprofessional communication and role clarification, as well as in their clinical teaching and practice. While there are limitations to the study because of the low followup rate, this approach supports the conclusion that providing clinical teachers with interprofessional education (IPE) related to their clinical teaching can result in reported modifications in their clinical teaching and practice.
\end{abstract}

Keywords: clinical practice; clinical teachers; interprofessional care; interprofessional workshop; learning outcomes

${ }^{*}$ Corresponding Author: Carole Orchard, Arthur Labatt Family School of Nursing,

Room G22, Siebens Drake Research Institute / Room 3312, FNB, London, Ontario, Canada, N6A 5B9

Email: corchard@uwo.ca

Journal URL: http://e-learning.coventry.ac.uk/ojs/index.php/pblh 
Orchard, C., Pederson, L.L., Allen, D., and Lam, H. (2017) 'Can Preparation of Clinical Teachers in IPC Concepts and Competencies Impact Their Approach to Teaching Students in Clinical Practice? A Promising Approach'. International Journal of Practice-based Learning in Health and Social Care, 5 (1), 98-115

\section{(c) 9 () $९$}

(c) 2017 Carole Orchard, Linda L. Pederson, Dianne Allen, and Halina Lam. This Open Access article is distributed under the terms of the Creative Commons Attribution Attribution-NonCommercial No Derivatives 4.0 International License (https://creativecommons.org/licenses/by-nc-nd/4.0/ ), which permits unrestricted non-commercial use, distribution, and reproduction in any medium, provided the original work is properly cited and is unaltered. 


\section{Introduction}

An interprofessional (IP) model of health care delivery is based on an integrated health care approach, which is patient-centered and uses collaborative practice achieved through effective and strong cross-disciplinary team work. "Interprofessional education occurs when students from two or more professions learn about, from and with each other to enable effective collaboration and improve health outcomes" (World Health Organization 2010: 13). Frequently the patient and/or family members are involved in all phases of the process. In comparison, a multidisciplinary model of care occurs when each profession teaches its own future professionals to assess, implement and evaluate health practices within the lens of a specific profession, often sharing conclusions with other professionals but without the patient or family present. Directional papers and Acts specifying guidelines for clinical practice issued by the government of Ontario's heath system are emphasizing the need for health professionals to practice within IP collaborative teams (HealthForceOntario 2007, Government of Ontario 2015, Ministry of Health and Long-Term Care 2015).

The concept of socialization occurs frequently in the IPE literature. In the past, the model was uni-dimensional, focusing only on the profession that the person was studying and did not take account of the roles of other professionals. This approach resulted in conflicts and role ambiguity when one professional did not realize the cross-fertilization that can occur across professions. In contrast, attention to social contact (Pettigrew 1998) and intergroup contact theories (Pettigrew and Tropp 2008) which are based on group socialization may assist in an understanding of the ongoing focus on professional specific socialization, and, further, may form a key underpinning theory for the basis of learning in IPE. Social contact theory suggests that when individuals form into social groups, they can become cohesive and create an allegiance to their members. Individuals outside of their group can be viewed as not having the same values and, therefore, this outgroup may not be trusted. Intergroup contact theory presents four conditions that can create an openness to new individuals, entering, or expanding the groups, as well as including other groups in their work. According to Pettigrew, these four conditions include: "learning about the outgroup, changed behavior, affective ties, and ingroup reappraisal" (Pettigrew 1998: 65). Thus, when professionals attempt to join interprofessional groups, it is essential for group members to assist new members in decreasing their anxiety about joining the group; show respect and empathy towards new members; and share in the knowledge, skills, and expertise they each bring into the group (Pettigrew and Tropp 2008). However, practitioners' educational preparation and socialization into their professions may often reflect an ingroup bias favoring their own profession, and may not be designed to meet the needs for interprofessional collaborative practice.

Since many health programs rely on practicing professionals to support students' experiential practice learning, guidance of these students in practice-based learning is often transferred to clinical teachers, who may be expert practitioners in multi-disciplinary but not necessarily in IP collaborative practice. Helping these clinical teachers gain an understanding of the concepts, competencies, and strategies needed to integrate IP patient-centered learning may potentially have a dual benefit - supporting IP learning in their students, and also helping to use these IP concepts and competencies in their own practice.

\section{Literature review}

Clinical teachers, who are tasked with educating learners who will join IP groups, may be faced with different challenges as compared to teachers who work with only one professional group (Freeth and Reeves 2004, Rees and Johnson 2007); these challenges may include lack of understanding of the IP collaborative approach, and of the skills necessary for working with patients and family members as team members. Thus, it is important to prepare clinical teachers to focus, not only on their own profession, but also on the importance of engaging other professions in practice settings (Freeman, Wright, and Lindqvist 2010, Rees and Johnson 2007, Anderson, Cox, and Thorpe 2009). Several authors have commented that stereotypes 
and rivalries can exist between health professionals, and can create roadblocks to effective collaboration (Derbyshire and Machin 2011, Harvey et al. 2002). One study has demonstrated that these negative stereotypes can be modified through post-licensure IP education (Carpenter 1995). In addition, a meta-analysis of six studies assessing the effectiveness of IPE interventions conducted by Reeves et al. (2013), found positive outcomes in patient satisfaction, increases in collaboration, and reductions in clinical error within an emergency department. There was also an increase in the management and competencies to deliver care for domestic violence victims, and mental health patients in four of the studies.

What are some of the potential benefits of IP education? Howkins and Bray (2008) reported that interprofessional education (IPE) improves students' learning experiences and optimizes patient treatment. Hallin et al. (2011) found that patients who received treatment from interprofessionally educated clinical teams, perceived and rated quality of treatment and care significantly higher compared to usual care by regular staff.

What are the skills and knowledge needed to deliver effective IP training? The 'PIPE' project (Promoting Interprofessional Education), surveyed sixteen IP clinical teachers in the UK, and found some common themes which included:

(1) Self-awareness as a facilitator;

(2) Ability to deal with conflicts and differences;

(3) Ability to promote positive group dynamic and relationship; and

(4) Ability to develop strong and effective lesson plans (Howkins and Bray, 2008).

Interestingly several authors have reported on the training of clinical teachers for teaching in IPE courses (Anderson, Manek, and Davidson 2006, Hunter et al. 2008, Hylin et al. 2007, Jacobsen et al. 2009, Kinnair, Anderson, and Thorpe 2012). Others have suggested key skills required (Freeman, Wright, and Lindqvist 2010, Banfield and Lackie 2009, Harvey et al. 2002). Some authors suggest strategies for teaching (Derbyshire and Machin 2011, Armitage, Connolly, and Pitt 2008, Craddock et al. 2006), but none were located that suggest a method for preparation of uni-professional clinical teachers to support IP student learning in practice.

\section{Interprofessional clinical teaching program}

In order to address the above noted gap in preparing clinical teachers to seek out interprofessional learning opportunities for their uni-disciplinary students, a program was designed providing an overview of theories and competencies related to IP client-centered practice. The structure of the workshops was designed to promote learning across professions by placing participants in IP groups. As well, the content was designed to incorporate the four themes identified above by Howkins and Bray (2008).

\section{Program development}

At Western University, Canada, the coordinator and staff within the Office of Interprofessional Health Education and Research (IPHER) faced challenges in developing and implementing an IPE practice program for cross-disciplinary students. First, a cost-effective solution was required. This meant trying to implement a program that would achieve the required goals, with no increase in costs. Second, since all health professional students already received supervised/preceptored practice experiences within their current programs, a question arose as to whether a shift in focus to clinical teachers rather than placement of cross-disciplinary teams of students supervised by an additional faculty member uniquely supporting only their IP learning in practice. In other words, should the focus be on trying to get IP students together into practice groups, or on improving the skills of each professional program's clinical teachers to support practice-based IP learning? 
The IPHER Curriculum Committee, comprised of faculty from each of the participating programs and representatives from the London Interprofessional Healthcare Students' Association (LIHSA), explored the above questions and worked collaboratively to create the Western University's Interprofessional Clinical Teaching Workshop. The decision was made to focus on the clinical teachers, with the overall purpose to prepare them to guide students in collaborative teamwork within practice settings. It was felt that what was being missed in the uni-professional approach was the deficiency in clinical teachers providing IP learning opportunities. This could be improved by developing the teachers additionally to their usual role to support their students' IP collaboration competencies, and in evaluating their abilities to practice as IP team members. To achieve the above, Mezirow's transformative learning theory (2000) and Pettigrew's intergroup contact theory (Pettigrew 1998, Pettigrew and Tropp 2008) were identified as the theoretical bases for the program. Mezirow's theory outlines the need to create an atmosphere where participants could challenge their existing assumptions related to practice models and the role of patients in their care. On the other hand, Pettigrew's theory (1998), and particularly Pettigrew and Tropp's (2008), reported on three mediators to intergroup contact (reductions of anxiety, increased empathy and respect towards each other, and clarification of roles) within learning groups. They provided evidence that these mediators would assist in allowing for learning about both the CIHC IP Collaboration Competency domains (Canadian Interprofessional Health Collaborative 2010) and for exploring how collaboration in their groups could be used to identify strategies to guide their students in developing their IP collaborative teams.

\section{Workshop content}

The workshop content is consistent with faculty development needs identified by Krautscheid, Kaakinen, and Warner (2008: 432), which include: (a) learn how to capitalize on teaching moments; (b) apply evidence-based teaching; and (c) adapt teaching to match varied student learning needs.

Bray's (2008) Delphi survey of interprofessional educators identified key focal areas for facilitator learning including: ability to "deal... with differences in similarities in professions; [gain an understanding of the] influence of power on group behaviour; [and its] effect on self-esteem and professional values; [the importance in clarity about] language barriers ..." (31). Therefore attention to providing a workshop environment that ensures participants are provided with opportunities to (a) work in IP groups and learn from each other about their roles; and (b) discuss the impact that uni-professional learning has on unique word usage, approaches to patient encounters, and varying communication patterns. Additionally, participants were provided with opportunities to explore systemic issues that impact socialization into specific professions and the impact on practice-based teamwork. All of these topics were integrated into the workshop protocol. Consequently, the workshops were designed to address Kirkpatrick and Barr's levels of 1, 2, and 3 (Gillan et al. 2011) (see Table 1)

Table 1. Adapted Barr-Kirkpatrick/Barr's levels of learning outcomes

\begin{tabular}{|l|l|}
\hline Level & Focus \\
\hline Level1 & Learners' reaction to the IP learning experience \\
\hline Level 2a & Modification of and changes in attitudes towards participating in IP group \\
\hline Level 2b & IP collaboration knowledge or skill acquisition \\
\hline Level 3 & Behavioral changes in professional practice \\
\hline Level 4a & Organizational changes with adoption of IPC delivery of care \\
\hline Level 4b & Patient/client involvement in their care leading to positive health outcomes \\
\hline
\end{tabular}


Workshops were held early in September 2010, 2011 and 2012. The 2010 workshop lasted for four hours; in the 2011 and 2012 workshops, the time was increased to six hours based on the feedback from participants in 2010. The target group was those who served as preceptors or direct supervisors of health and social program students' learning in practice settings. Programs included were: medicine, dentistry, nursing (BScN and practical), physical therapy, occupational therapy, audiology, speech language pathology, nutrition and dietetics, respiratory therapy, pharmacy technician, clinical psychology, and social work. The purpose was to assist practicebased teachers in guiding and assessing students from the above programs for effective collaborative teamwork within practice settings (See Appendix for the Workshop Agenda).

Goals of the workshop included participants gaining:

- Understanding of the roles, knowledge, skills, and expertise of members of IP teams in practice settings;

- Challenging existing assumptions about IP collaborative practice and patient-centred care;

- Exploring effective IP teaching strategies to support demonstration of IP collaboration competencies; and

- Exploring approaches that may be used to assess the demonstration of IP collaboration competencies.

The purpose of this study was to explore the self-reported impact of the workshop on the socialization, collaborative practice, and teaching approaches of these teachers. In other words the questions of interest were:

(1) Do clinical teachers who participate in a workshop report that it was helpful for IPE socialization in their students and colleagues?

(2) Do clinical teachers who participate in a workshop report that it was helpful for collaboration among their students and colleagues?

(3) Do clinical teachers who participate in a workshop report that it was helpful for IP teaching strategies for their students and colleague in clinical settings?

Ethics approval was obtained from Western University's Human Ethics Review Board.

\section{Methodology}

A pre-post program evaluation approach was used to assess the effect of the IP clinical teaching workshop on clinical teachers' seeking out IP learning opportunities for their students and their socialization, and adoption of collaborative IP client-centered practice. Information was collected from a pre-workshop survey, workshop feedback forms, and a post-workshop survey that also included four open-ended questions. The surveys were available online, with responses requested online as well. Two instruments were used: the Interprofessional Socialization \& Valuing Scale (ISVS) (King, Shaw, Orchard, and Miller 2010), to assess socialization change towards IPC; and the Assessment of Interprofessional Team Collaboration Scale (AITCS) (Orchard, King, Khalili, and Bezzina 2012), to assess application of IP collaboration competencies in teamwork.

Interprofessional Socialization \& Valuing Scale (ISVS): The ISVS is a 32-item self-report tool that uses a 7-point Likert scale ( $7=$ a very great extent, to $1=$ not at all), to measure an individual's perceived valuing of working together, abilities to work together, and comfort in working interprofessionally. Reliability of the ISVS was established using Cronbach's alpha for internal consistency, which ranged from 0.79 to 0.89 , and an overall rating of 0.90 . Construct validity of the tool was established using principle component analysis (PCA) and account for $48.7 \%$ of the variance.

Assessment of Interprofessional Team Collaboration Scale (AITCS): The AITCS is a diagnostic instrument developed to assist health care practitioners to determine how well they and their 
colleagues are collaborating within their teams. The tool is comprised of 37 items grouped within three subscales (partnership/shared decision making, coordination, and cooperation) which are assessed using a 5-point Likert scale (5 = always, to $1=$ never). Reliability of the instrument was assessed using Cronbach's alpha which is 0.98 and its item internal consistency correlation ranges from 0.80 to 0.97 . Construct validity was assessed using both exploratory factor analysis (EFA) and confirmatory factor analysis (CFA). The EFA revealed a 3-factor solution explaining $58 \%$ of the variance, and the CFA accounted for a total variance of $61.02 \%$ across the three factors (partnership/shared decision making, coordination, and cooperation).

\section{Study participants}

A total of 129 clinical teachers participated in three workshops (September 2010 [ $n=49], 2011$ [ $n=39]$, and 2012 [ $n=41]$. Each of the annual workshops was divided into groups of five or six members. Only 30 of the 129 participants (23.3\%) provided responses to the AITC, ISVS and the open-ended questions for the post-workshop survey (see below). Of the those who responded, 33.3\% $(n=10)$ were registered nurses, $14.8 \%(n=4)$ were imaging technologists, $22.2 \%(n=7)$ were dietitians or speech language pathologists (SLPs;) two dentists, two spiritual/pastoral care, an individual occupational therapist (OT), a physical therapist (PT), a therapy assistant, and two who did not identify their profession. The group was predominantly female (27/30). Three-quarters of the group were between 40 to 59 years. Their years in practice were distributed across a wide range of experience with the largest group reporting being in practice from 21 to 30 years (34\%) followed by $31 \%$ stating more than 30 years, and with a smaller group of $24.1 \%$ commenting they had been practicing from 11 to 20 years. The largest percentage of respondents worked full time $(81.5 \%)$ with only $11.1 \%$ working part-time, and the smallest group (7.4\%) employed casually. Two-thirds of the respondents had a masters degree $(65.5 \%)$, with only $13.8 \%$ reporting a bachelor degree, and one reporting a PhD. Less than $10 \%$ commented that their highest educational preparation was a diploma.

Table 2. Number of responses by data source by year of data collection in the study.

\begin{tabular}{|l|l|l|l|l|l|}
\hline \multicolumn{2}{|l|}{ Data Source } & 2010 N & $\begin{array}{l}\text { Year } \\
\text { 2011 N }\end{array}$ & 2012 N & 2013 N \\
\hline \multicolumn{2}{|l|}{ Pre-Workshop Survey } & & & & \\
\hline & ISVS & $20 / 49$ & $20 / 39$ & $29 / 41$ & \\
\hline & AITCS & & $14 / 39$ & $31 / 41$ & \\
\hline Workshop feedback & $26 / 49$ & $31 / 39$ & $27 / 41$ & \\
\hline Post-workshop survey & & & & \\
\hline & ISVS & & & & $21 / 30$ \\
\hline & AITCS & & & & $21 / 30$ \\
\hline
\end{tabular}

\section{Data collection}

Three means to assess learning from the workshop were used: a feedback form assessing the satisfaction with the workshop arrangements as well as a rating of their learning based on the intended goals, and four open-ended questions and two instruments - ISVS (King et al. 2010) and AITCS, (Orchard et al. 2012) - were completed online pre-workshop and post-workshop (see Table 2). In the post-workshop data collection, the four open-ended questions were added to the online survey following the AITCS and ISVS. All participants who attended the 2010, 2011, and 2012 workshops were sent an email (based on their workshop registration email addresses) requesting completion of a post-workshop survey with the addition of the four open- 
ended questions. Two reminders were sent two weeks after the first and subsequent requests for a total of three contacts. The workshop feedback forms and the online surveys did not contain participant identifiers; therefore, the information could not be linked to either pre-or postworkshop responses.

Pre-Workshop Surveys. Workshop participants were requested to complete two instruments ISVS (King et al. 2010), the AITCS (Orchard et al. 2012) prior to attending the 2011 and 2012 workshops. However, only the ISVS was completed prior to the 2010 workshop.

Workshop Feedback Data. At the end of each workshop, participants were encouraged to complete session feedback forms. One section of these forms allowed participants to rate the effectiveness of their learning from the event using a five-point Likert scale $(5=$ strongly agree to 1 = strongly disagree). The items were generated based on the workshop goals: the items were summed to arrive at a learning effectiveness score for the workshop which could range from a mean of 10 to 50 .

Table 3. Workshop feedback items assessing participant learning.

\begin{tabular}{|l|}
\hline Statements rated from $\mathbf{1}$ (strongly disagree) to $\mathbf{5}$ (strongly agree): \\
\hline I gained an enhanced understanding of what interprofessional collaborative practice means \\
\hline I gained an enhanced understanding of what collaboration for patient care means \\
\hline I have gained an enhanced understanding of what constitutes collaborative teamwork \\
\hline I have gained a clearer understanding of the roles, knowledge, skills, and expertise of other team \\
members
\end{tabular}

Post-Workshop Data: Thirty of the workshop respondents from the 2010, 2011, and 2012 workshops completed the post-workshop survey (using the ISVS and AITCS) from a total of 129 participants, thirteen were from either the 2010 or 2011 workshops while the remaining 17 were from the 2012 workshop.

Open Ended Questions. Participants (post-workshop) were asked how they were socializing their students, how they thought they were influencing collaborative practice in their settings, and finally what changes had occurred in their teaching strategies (see Table 4). 
Table 4. Open ended questions added to the Post-Workshop Survey Instruments.

\section{Open ended specific Questions:}

Please comment on any changes you have made to your teaching approaches since the workshop;

Please comment on any changes you have made in the way you guide students in developing their professional role since the workshop;

Please comment on any changes to performance expectations for students you have made since the workshop; and

Please comment on any changes you have made in your own practice as a result of your learning in the workshop.

\section{Data analysis}

Workshop feedback data were analyzed using descriptive statistics to compare learning effectiveness scores for the three groups. The qualitative data were analyzed using descriptive qualitative content analysis as described by Sandelowski (2000). According to Sandelowski "qualitative descriptive study is the method of choice when straight description of phenomena are desired" (2000: 334). Analysis includes coding, categorization, and identification of themes, however it keeps close to the data and is less interpretive (Sandelowski 2000). Since we were interested in learning what actions or strategies participants were using from the workshop, this form of qualitative analysis was chosen.

\section{Results}

The findings from data obtained from these three workshops are organized as follows. First, the ratings of program effectiveness are presented, followed by the summaries of the pre-post comparison for total and subscale scores from the AITCS and ISVS, and finally themes from the open ended responses to the four additional questions in the post-survey are presented.

\section{Workshop Learning Effectiveness Scores}

Ratings for each item related to the rating of workshop goal achievement was obtained by summing all the ten item ratings (used a five-point rating scale; total possible score $=50$ ) on participant's perception of their learning. These items parallel the goals of the workshop (see Table 5). Learning effectiveness ratings from the respondents were found to be, in general, quite high.

Table 5. Learning effectiveness scores from participants ratings of their learning from workshops. (Legend: $n=$ number of respondents; $M=$ mean; Sum = total; $\%=$ percent of total possible responses)

\begin{tabular}{|l|l|l|l|l|}
\hline Year & $n$ & $M$ & Sum & $\%$ \\
\hline 2010 & 26 & 41.85 & 1088 & 83.7 \\
\hline 2011 & 31 & 42.85 & 1328 & 85.7 \\
\hline 2012 & 27 & 41.67 & 1125 & 83.3 \\
\hline
\end{tabular}


Pre-Post Survey Results

Survey data were summarized using the scoring guidelines for each of the instruments used (Orchard et al. 2012, King et al. 2010). The analysis of pre- and post-workshop data were combined for the three workshops and analyzed using independent sample t-tests to determine the mean differences across the workshops. (Given that there were no identifiers on the surveys, it could be the case that some individuals completed both forms, and therefore the use of independent t-tests may have overestimated the standard error).

Approximately $50 \%$ of respondents completed the ISVS and AITCS for both $2011(n=20)$ and $2012(n=23)$ while only $40 \%$ completed the ISVS in 2010 (Note: in 2010 only the ISVS was used at the pre-test). These findings may reflect the fact that each of the participants was considering different specific teamwork experiences in their responses rather than similar experiences from the workshops. In the post-test results, the only significant difference between pre- and post-scores were decreases in Partnership and Collaboration (See Table 6 below).

Table 6. Analysis of interprofessional team collaboration and socialization amongst participants both pre- and post-workshops (Legend: $\mathbf{n}=$ number of respondents; $\mathbf{M}=$ mean; SD = standard deviations, MIS = mean item score)

\begin{tabular}{|c|c|c|c|c|c|c|c|c|c|c|}
\hline & \multicolumn{5}{|c|}{ PRE- } & \multicolumn{5}{|c|}{ POST- } \\
\hline Variable & $n$ & $M$ & $S D$ & Sum & MIS & $n$ & $M$ & $S D$ & Sum & MIS \\
\hline AITCS & & & & & & & & & & \\
\hline Collaboration ${ }^{\star \star}$ & 44 & 137.14 & 19.03 & 6034 & 4.03 & 17 & 124.65 & 13.09 & 2119 & 3.37 \\
\hline Partnership & 52 & 73.25 & 10.9 & 3809 & 3.86 & 22 & $64.50^{*}$ & 6.43 & 1419 & 3.39 \\
\hline Cooperation & 52 & 43.13 & 6.1 & 2243 & 3.59 & 25 & 41.84 & 6.4 & 1046 & 3.49 \\
\hline Coordination & 50 & 21.86 & 5.2 & 1093 & 3.64 & 25 & 21.44 & 5.6 & 536 & 3.57 \\
\hline ISVS & & & & & & & & & & \\
\hline Socialization $^{\star \star}$ & 48 & $\begin{array}{l}111.0 \\
0\end{array}$ & 15.8 & 5328 & 3.26 & 22 & 104.59 & 12.9 & 2300 & 3.08 \\
\hline $\begin{array}{l}\text { Comfort } \\
\text { working }\end{array}$ & 52 & 27.19 & 3.9 & 1414 & 3.77 & 23 & 26.04 & 3.1 & 599 & 2.89 \\
\hline $\begin{array}{l}\text { Ability to work } \\
\text { with others }\end{array}$ & 54 & 37.98 & 6.4 & 2051 & 3.46 & 23 & 35.40 & 4.9 & 1213 & 3.22 \\
\hline $\begin{array}{l}\text { Valuing } \\
\text { working with } \\
\text { others }\end{array}$ & 50 & 45.86 & 7.7 & 2283 & 3.28 & 24 & 42.50 & 7.1 & 1020 & 3.04 \\
\hline
\end{tabular}

${ }^{\star *}$ total score ${ }^{*}$ significant at $p 0.05$

\section{Descriptive themes: Post-program reported changes}

Twenty-seven of the 30 respondents in the post-survey, reported changes in their teaching and practice as a result of the workshop. Of the three respondents who did not report any changes, two stated they had not been teaching, the other respondent provided no comment. These 
responses were coded within each question, categorized and finally overall themes for all categories were arrived at including: patient as a team member; fostering team development skills; valuing of roles, expertise, and perspectives; nurturing partnerships; and role modeling of IPC.

\section{Patient as a team member}

Respondents discussed how they focused on ensuring that their students viewed the patient as a member of the IP team. 'I try to impress on the student that they must consider what the patient feels that their needs are and not what the student feels they need.' 'I'm a more confident advocate for client-centered care.' Thus the respondents were applying the essence of what patient-centered care means within IP client-centered collaborative practice.

\section{Fostering team development skills}

The respondents discussed how they focus on roles between health professionals, and how to help students learn about roles other than their own discipline's. 'Place students with other disciplines for shadowing opportunities, encourage them to participate in multidisciplinary rounds.' 'I encourage the students to think of who else is included in the team to assist the client.' 'I ask them to explain their role more and I ask them to pay attention to other roles more.' They also were more likely to emphasize the importance of listening and communicating with others, as well as how to negotiate and facilitate care discussions with other health professionals, and addressing conflict resolution. 'More aware of conflict resolution, negotiation and facilitation skills.' 'I now stress the importance of better communication and listening skills...' Three further IP collaboration competencies were identified within this theme including role clarification, IP communication, and IP conflict resolution.

\section{Valuing of roles, expertise, and perspectives}

Respondents shared how they have become more conscious of what other professional's perspectives on care might be, and use this information to help in shaping their teaching of students. 'I feel I more overtly consider the other profession's perspective.' 'Since the workshop I have sought out information from the various disciplines before teaching.' 'I ask my students more about who they could refer things to.' They also shared how they seek out more feedback from students, and also for advice from other health professionals about care planning. 'I am more mindful of the power imbalance and attend to unspoken feedback, and encourage students to ask more questions.' '...[M]ore open and comfortable to ask other disciplines for advice and integrate into plan of care.' These comments suggest that the respondents also gained an understanding of system issues that have created a uni-professional perspective towards practice, and how they are working to expand that learning to be more inclusive of other health professionals outside of their own discipline.

\section{Nurturing partnerships}

Respondents discussed a variety of strategies they were using to bring into learning the perspectives of other health professionals. 'Encourage the preceptors of students to arrange shadow opportunities across the spectrum of inter-disciplinary exposure during placements.' 'I seek out opportunities for students to meet others in similar and different disciplines.' 'Encourage students to ask questions, initiate discussions with other health care professionals that are involved in the client's care.' 'I bring in practitioners from other professions to deliver lectures.' Again in this theme, comments were associated with the processes respondents were using to allow their students to learn about other health professionals, and their roles in patient care.

\section{Role modeling of IPC}

Respondents shared how they are working to emulate practice. 'I am sure to invite my students to observe and offer feedback to me on my role.' 'I am passionate about this topic and model of practice.' 'I am more vocal about being part of a team approach with students.' They also shared how to create the space for students in their profession to learn from those, both students and practitioners about others roles. "I try to have the students talk with other students in different professions.' 'I introduce them to the IP team and get the team to discuss their roles.' 
There was evidence in these comments as to how the respondents were trialing new approaches to their teaching, incorporating in particular role clarification across professions.

Changing ways of thinking about evaluation of practice

'[l am] incorporating the new CNO [College of Nurses of Ontario] guidelines for interprofessional competency', 'used different evaluation forms', 'performance expectations are dictated by each university.' These comments came from a nurse who sought out what the expectations were for students demonstrating an IP competency within the national entry to practice competencies for nurses.

\section{Discussion}

In the current workshops, the participants were first introduced to a clear understanding of the differences between the predominant multi-disciplinary models of care as contrasted to IP client-centered collaborative practice models of care in the topic 'what's similar to and what's different from our current practice'. They were further given the opportunity to explore in interprofessional small groups strategies to overcoming a profession-specific orientation to embracing more cross-disciplinary interactions in students' practice through 'tips from the trenches' and 'pushing into uncharted territories'. This approach is in keeping with Freeman, Wright, and Lindqvist's (2010) principles for facilitation of effective IP team working - (a) share a common philosophy and vision of IPE and IPL; (b) awareness of context of IPL ... understanding of core IPL; (c) clear understanding of role to give student support; and (d) prepare for role of support cross-professional groups to foster knowledge, skills, attitudes and behaviors needed for IP teamwork (379).

The workshop format and content were designed to support participants' learning about the roles and interests of those from several different professions. Two theories guided the development of the workshop: intergroup contact theory (Pettigrew 1998) and Mezirow's transformative learning theory (2000). Intergroup contact theory proposes four conditions for optimal intergroup contact: 'equal group status within the situation', 'common goals', 'intergroup cooperation' and 'authority support' (Pettigrew and Tropp 2008: 922). In the workshop, participants were divided into interprofessional groups from a variety of agencies. Hence, each member had equal status in the group and few usually knew the others at the beginning of the day. Small group work during the workshop helped to create opportunities to develop common goals in their respective groups as well as intergroup cooperation. All participants received their institutional support to attend the workshop. Thus all the conditions for intergroup contact were also created within the workshop.

The learning provided within the workshop may also be related to Jarvis' work on learning to be a person in society (Jarvis 2009). Jarvis suggests that learning is a social process. The workshop, by bringing people from different professions together in small groups, created social processes. Hence, how a workshop participant has been socialized into, and learned the role enactment of, his/her profession becomes a 'taken for granted' way to function. Hence, it appears from some of the descriptive comments that those respondents felt some of their previously held beliefs about their norm of practice were challenged through their discussions in the small groups. Challenges to the status quo creates a disjuncture in the individual (Jarvis 2009). The individual then either tries to give meaning to what has been shared in the context of their current practice or chooses not to. Of the study respondents, three out of the group may have considered (for a variety of reasons) to not change their practice, while the other $27 \mathrm{did}$ make some efforts to introduce varying degrees of change. If the challenge or disjuncture is sufficiently meaningful, the individual may then transform their previous practice to incorporate the new learning; if not there will be no change (Jarvis 2009). Thus those respondents who reported changes in their practice may have done so by transforming previous practice and adding their new learning. This outcome is also reflective of Mezirow (2000) and Brookfield's (1987) assertion that critical thinking is an outcome of a challenge to previously held assumptions or beliefs. Thus the outcome of this study presents evidence that a portion (at least 
27 of the 30 who responded) of participants may have felt disjuncture in their previous beliefs about practice, and have taken action to transform both their teaching of learners and also within their own professional practice. The changes chosen by the 27 respondents are also aligned with the CIHC IP collaboration competency domains of patient/client centered care, IP communication, role clarification, and (to some extent) IP conflict resolution (Canadian Interprofessional Health Collaborative 2010).

The workshop was designed to address Kirkpatrick and Barr's levels 1, 2, and 3 (Orchard 2015) as set out in Table 1. The findings from the feedback analysis of participants' rating of their own learning to the objectives of the workshop demonstrated that Level 1 - reaction to learning was addressed. The analysis of the comments demonstrated that participants felt the need to re-focus their guiding of students onto the roles of health professionals, and to being more patient-centered. Thus the workshop did address Level 2a by creating a shift in attitudes among the participants around these key areas. Respondents discussed how they have students focus on the role of the patient in their care, and also provided examples of shadowing experiences for students to learn about other professionals' roles. These changes may be attributed to their shifts in attitudes gained from the workshop. The comments and ratings around participant learning also seemed to reflect new knowledge and skill learning, leading to their sharing ideas of how they focus on IP learning in students, and may also reflect the ratings of the value of the workshop to them; thus addressing Level $2 \mathrm{~b}$. Some respondents discussed how they share their new learning gained from the workshop with others as well.

The post-evaluation participant sharing of comments related to the open-ended questions seemed to provide insights into how they used the learning from the workshop to introduce some changes in how they guided students in their learning. Hence, Level 3 - focusing on changes in participants' practice - was also addressed.

While all of the $\mathrm{CIHC}$ competencies were addressed in the workshop, participants discussed application - at varying levels - of five of the six domains (patient/client/family/community centered care; interprofessional communication; role clarification; team functioning; interprofessional conflict resolution) (Orchard and Bainbridge 2016). The shared changes in their teaching and practice found in the post-evaluation survey, focused on patient/clientcentered care, IP communication, role clarification, and (to a lesser degree) team functioning and IP conflict resolution. There were no comments associated with IP collaborative leadership. This may be an expected outcome as the focus on the workshop was intended to prepare participants for expanding their focus on uni-professional student supervision by helping their students to seek out interprofessional learning opportunities. Perhaps a further workshop is needed to build onto the $\mathrm{CIHC}$ competency domains more fully with further strategies IP collaborative leadership, team functioning, and IP conflict resolution.

The learning impacts reported by the respondents, in both their student learning facilitation and their own practice, were a welcome and a surprising finding, given that we were not expecting immediate changes. Hence, we learned the need for multi-method appraisals of learning when using a workshop as an evaluative intervention. In this case, two of the three approaches reported positive findings - the workshop feedback data and the post-survey open-ended questions.

Overall, our findings do provide some support for each of the study questions:

(1) Do clinical teachers who participate in a workshop report that it was helpful for IPE socialization in their students and colleagues?

(2) Do clinical teachers who participate in a workshop report that it was helpful for collaboration among their students and colleagues?

(3) Do clinical teachers who participate in a workshop report that it was helpful for IP teaching strategies for their students and colleague in clinical settings? 
The above findings do provide some support for each of these study questions. However, these findings must be considered with caution because of the small size of the sample.

\section{Limitations}

The low rate of responses across the three workshops, limits the generalizability of the findings. The follow-ups were not planned in advance; therefore follow-ups were conducted without any attempt to update contact information. Some of the contact information may not have been up to date, and as a result the follow-ups may not have reached the intended recipients. Possibly providing information in advance about the follow-ups, and the importance of providing information, may have helped to improve the response rate. In addition, the failure to collect respondent identifiers in the pre- and post-surveys, and feedback forms, prohibits testing for specific individual changes over time. We could not identify whether those individuals who found the experience more positive were more likely to reply. Information on professional affiliation was collected so that it is possible to identify the groups of professionals who responded. The failure of the pre- and post-survey ratings to provide any statistically significant change in the respondents' socialization or team collaboration scores may mean that these measures are not appropriate for examining the outcome for these workshops. The participants were from a diverse group of organizations and rarely were part of the same team. The AITCS is designed to reflect on a specific team and its members. Hence, each participant may have considered the value of working together, but not necessarily in the current context. The qualitative data may begin to provide some indication of the potential of these workshops, and should be explored in future studies on, and collaboration in IPC in, future workshops.

\section{Conclusion}

We set out to assess whether clinical teachers reported that the workshops were helpful for incorporating IP learning in their uni-professional teaching. We found statistically significant differences in overall collaboration and in the partnership sub-scale of the AITCS, but not in the other subscales albeit with a lower sum between the pre- and post- data collection. The themes emerging document three main areas the respondents focused on in their teaching and practice: patient-centered care, role clarification, and IP communication. Since these relate to three of the six CIHC IP Competencies (Canadian Interprofessional Health Collaborative 2010), the outcome of this short, six-hour workshop may contribute to preparing clinical teachers of pre-licensure learners with learning opportunities for interprofessional collaboration.

\section{Acknowledgements}

We wish to express our thanks to the clinical teachers who attended the workshops and completed the pre- and post-tests, and especially to those who took the time to share their uses of their learning. 


\section{References}

Anderson, E.S., Cox, D., and Thorpe, L.M. (2009) 'Preparation of educators involved in interprofessional education.' Journal of Interprofessional Care, 23 (1), 81-94 https://doi.org/10.1080/13561820802565106

Anderson, E., Manek, N., and Davidson, A. (2006) 'Evaluation of a model for maximizing interprofessional education in an acute hospital.' Journal of Interprofessional Care, 20 (2), 182 -194 http://dx.doi.org/10.1080/13561820600625300

Armitage, H., Connolly, J., and Pitt, R. (2008) 'Developing sustainable models of interprofessional learning in practice - The TUILIP project.' Nurse Education in Practice, 8, 276-282 https://doi.org/10.1016/j.nepr.2007.10.004

Banfield, V. and Lackie, K. (2009) 'Performance-based competencies for culturally responsive interprofessional collaborative practice.' Journal of Interprofessional Care, 23 (6), 611620 https://doi.org/10.3109/13561820902921654

Bray, J. (2008) 'Interprofessional facilitation skills: Evidence from a Delphi research survey.' In Preparing for Interprofessional Teaching: Theory and practice. ed. by Howkins, E. and Bray, J. Abingdon, UK: Radcliffe Publishing, 27-39

Brookfield, S.D. (1987) Developing Critical Thinkers: Challenging Adults to Explore Alternative Ways of Thinking and Acting. San Francisco, CA: Jossey-Bass

Canadian Interprofessional Health Collaborative. (2010) A National Interprofessional Competency Framework. [online] available from http://www.cihc.ca/files/CIHC IPCompetencies Feb1210.pdf [3 April 2017]

Carpenter, J. (1995) 'Doctors and nurses: Stereotypes and stereotype change in interprofessional education.' Journal of Interprofessional Care, 9, 151-161 https://doi.org/10.3109/13561829509047849

Craddock, D., O'Halloran, C., Borthwick, A., and McPherson, K. (2006) 'Interprofessional education in health and social care: Fashion or informed practice?' Learning in Health and Social Care, 5 (4), 220-242 https://doi.org/10.1111/i.1473-6861.2006.00135.x

Derbyshire, J.A. and Machin, A.I. (2011) 'Learning to work collaboratively: Nurses' views of their pre-registration interprofessional education and its impact on practice.' Nurse Education in Practice, 11, 239-244 https://doi.org/10.1016/j.nepr.2010.11.010

Freeman, S., Wright, A., and Lindqvist, S. (2010) 'Facilitator training for educators involved in interprofessional learning.' Journal of Interprofessional Care, 24 (4), 375-385 https://doi.org/10.3109/13561820903373202

Freeth, D. and Reeves, S. (2004) 'Learning to work together: Using the presage, process, product (3P) model to highlight decisions and possibilities.' Journal of Interprofessional Care, 18 (1), 43-56 https://doi.org/10.1080/13561820310001608221

Gillan, C., Lovrics, E., Halpern, E., Wiljer, D., and Harnett, N. (2011) 'The evaluation of learner outcomes in interprofessional continuing education: A literature review and an analysis of survey instruments.' Medical Teacher, 33, e461-e470 http://dx.doi.org/10.3109/0142159X.2011.587915

Government of Ontario (2010) Excellent Care for All Act, 2010 S.O. 2010 c.14. Toronto, ON. Retrieved from http://www.health.gov.on.ca/en/pro/programs/ecfa/legislation/act.aspx 
Hallin, K., Henricksson, P., Dalén, N., and Kiessling, A. (2011) 'Effects of interprofessional education on patient perceived quality of care.' Medical Teacher, 33, e22-e26 http://dx.doi.org/10.3109/0142159X.2011.530314

Harvey, G., Loftus-Hills, A., Rycroft-Malone, J., Titchen, A., Kitson, A., McCormack, B., and Seers, K. (2002) 'Getting evidence into practice: the role and function of facilitation.' Journal of Advanced Nursing, 37 (6), 577-588 https://doi.org/10.1046/j.13652648.2002.02126.x

HealthForceOntario, 2007. Interprofessional Care: A Blueprint for Action in Ontario. Toronto, ON: Government of Ontario. [online] available from http://www.ontariostrokenetwork.ca/stroke-rehabilitation-resource-centre/wpcontent/uploads/sites/2/2013/08/01-ipc-blueprint-july-2007-en.pdf [3 April 2017]

Howkins, E. and Bray, J. (eds.) (2008) Preparing for Interprofessional Teaching: Theory and Practice. Abingdon, UK: Radcliffe Publishing

Hunter, J., Watt-Watson, J., McGillion, M., Raman-Wilms, L., Cockburn, L., Lax, ... Salter, M.(2008) 'An interfaculty pain curriculum: Lessons learned from six years experience.' Pain, 140, 74-86 http://dx.doi.org/10.1016/j.pain.2008.07.010

Hylin, U., Nyholm, H., Mattiasson, A-C, and Ponzer, S. (2007) 'Interprofessional training in clinical practice in a training ward for healthcare students: A two-year follow-up.' Journal of Interprofessional Care, 21 (3), 277-288 http://dx.doi.org/10.1080/13561820601095800

Jacobsen, F., Fink, A.M., Marcussen, V., Larsen, K., and Hansen, T.B. (2009) 'Interprofessional undergraduate clinical learning: Results from a three year project in a Danish Interprofessional Training Unit.' Journal of Interprofessional Care, 23 (1), 30-40 https://doi.org/10.1080/13561820802490909

Jarvis, P. (2009) 'Learning to be a person in society: Learning to be me.' In Contemporary Theories of Learning: Learning Theorists...In their Own Words. ed. by Illeris, K. London: Routledge, 21-34

King, G., Shaw, L, Orchard, C.A., and Miller, S. (2010) 'The interprofessional socialization and valuing scale: A tool for evaluating the shift toward collaborative care approaches in health care settings.' Work: A Journal of Prevention, Assessment and Rehabilitation, 35, 77-85 doi: 10.3233/WOR-2010-0959

Kinnair, D.J., Anderson, E.S., and Thorpe, L.N. (2012) 'Development of interprofessional education in mental health practice: Adapting the Leicester Model.' Journal of Interprofessional Care, 26, 189-197 https://doi.org/10.3109/13561820.2011.647994

Krautscheid, L., Kaakinen, J., and Warner, J.R., (2008) 'Clinical faculty development: Using simulation to demonstrate and practice clinical teaching.' Journal of Nursing Education, 47 (9), 431-434 https://doi.org/10.3928/01484834-20080901-05

Mezirow, J. (ed.) (2000) Learning as Transformation: Critical Perspectives on a Theory in Progress. San Francisco, CA: Jossey-Bass

Ministry of Health and Long-Term Care (2015) Patients First Act: Action Plan for Health Care. Toronto, ON: Government of Ontario. [online] available from http://www.health.gov.on.ca/en/ms/ecfa/healthy change/docs/rep patientsfirst.pdf [3 April 2017] 
Orchard, C., (2015) 'Evaluation of continuing interprofessional client-centered collaborative practice programs.' In Interprofessional client-centered collaborative practice: What does it look like? How can it be achieved? ed. by Orchard, C. and Bainbridge, L. Hauppauge, N.Y.: Nova Science Publishers 161-170.

Orchard, C. and Bainbridge, L. (2016) 'Competent for collaborative practice: What does a collaborative practitioner look like and how does the practice context influence interprofessional education?' Journal of Taibah University Medical Sciences, 11 (6), 526-532 https://doi.org/10.1016/i.jtumed.2016.11.002

Orchard, C., King, G., Khalili, and Bezzina, M.B. (2012) 'Assessment of Interprofessional Team Collaborative Practice (AITCS): Development and testing of the instrument.' Journal of Continuing Education in the Health Professions, 32 (1), 58-67 https://doi.org/10.1002/chp.21123 Available from http://onlinelibrary.wiley.com/doi/10.1002/chp.21123/full [3 April 2017]

Pettigrew, T.F. (1998) 'Intergroup contact theory.' Annual Review of Psychology, 49, 65-85 http://dx.doi.org/10.1146/annurev.psych.49.1.65

Pettigrew, T.F. and Tropp, L.R. (2008) 'How does intergroup contact reduce prejudice? Metaanalytic tests of three mediators.' European Journal of Social Psychology, 38, 922-934 https://doi.org/10.1002/ejsp.504

Rees, D. and Johnson, R. (2007) 'All together now? Staff views and experiences of a prequalifying interprofessional curriculum.' Journal of Interprofessional Care, 21 (5), 543555 https://doi.org/10.1080/13561820701507878

Reeves, S., Perrier, L., Goldman, J., Freeth, D., and Zwarenstein, M. (2013) 'Interprofessional education: effects on professional practice and health care outcomes (Review).' The Cochrane Library, 3, 1-47. Retrieved from http://www.cochranelibrary.com/ [11 October 2016]

Sandelowski, M. (2000) 'Whatever happened to qualitative description?' Research in Nursing and Health, 23 (4), 334-340 https://doi.org/10.1002/1098-240X(200008)23:4<334::AlDNUR9>3.0.CO;2-G

World Health Organization (2010) Framework for Action on Interprofessional Education Collaborative Practice. Geneva, Switzerland: WHO. available from http://www.who.int/hrh/resources/framework action/en/ [3 April 2017] 


\section{Appendix 1.}

\section{IP Clinical Teaching Workshop Agenda}

\section{Workshop Agenda}

0800 Refreshments and registration

0830 Introduction to IPE and collaborative practice - 'What's similar to and what's different form our current practice'

0920 Video - Ineffective/Effective Teamwork

0935 Exemplar: Teaching interprofessionally in Practice - 'Tips from the trenches"

0955 Small Groups: Strategies in using competencies in practice

1015 REFRESHMENT BREAK

1030 Sharing key strategies with large group

1050 Exemplar: Dyad of Clinical Teacher and Student

1100 Integrating professional and interprofessional learning -- 'Pushing into uncharted territories'

1130 Small Group Work: Learning Activities in Practice - Expanding the focus beyond one profession'

1150 Sharing key IP learning with large group

1205 LUNCH

1250 How to assess for IP collaboration competence - 'Knowing when IP Competence is there!'

1315 Small Group Work: Assessing for competencies

1345 Sharing approaches with large group

1400 Case study

1425 Workshop summary and reflecting on learning 